\title{
ALTAS HABILIDADES E O DESAFIO DO ATENDIMENTO
}

Célia Maria Ferreira Barreto

Professora do Colégio Pedro II. Unidade São Cristóvão I. Rio de Janeiro. Pedagoga e Especialista em Altas Habilidades pela Universidade do Estado do Rio de Janeiro. Rio de Janeiro. Brasil. Mestre em Psicologia Social pela Universidade Salgado de Oliveira - UNIVERSO.

\author{
Marsyl Bulkool Mettrau \\ Doutora em Educação e Psicologia da Educação pela Universidade Minho. Braga, Portugal. \\ Professora titular da Universidade Salgado Oliveira. Niterói.
}

\begin{abstract}
Resumo
O Estudo foi realizado em uma escola federal de ensino, localizada no Rio de Janeiro. Estabeleceu como objetivos gerais investigar as representações sociais dos professores sobre as altas habilidades e a existência da indicação de alunos com esse perfil para atendimento. Utilizou duas amostras diferenciadas. Uma formada de 36 professores que atuavam do $1^{\circ}$ ao $9^{\circ}$ ano do ensino fundamental e do $1^{0}$ ao $3^{\circ}$ ano do ensino médio e a uma outra composta por quatro Setores do colégio, responsáveis pela registro histórico dos alunos. Aplicou a análise de conteúdo no tratamento dos dados obtidos. Os resultados mostraram que os professores respondentes têm representações sociais sobre altas habilidades e que não há alunos com altas habilidades matriculados na instituição, segundo os Setores pesquisados. A pesquisa sugere urgência no implemento de ações inclusivas para as altas habilidades nessa escola, assim como a continuidade nessa investigação.
\end{abstract}

Palavras-chave: altas habilidades, representações sociais, atendimento.

\section{HIGH ABILITY AND THE CHALLENGE OF COUNSELING}

\begin{abstract}
The study took place in a Public Federal School in Rio de Janeiro. The overall objectives investigated social representation teachers have about high abilities and any existing indication of such students to be directed to specific learning and counseling programs. Two different groups were taken as samples. The first was formed by 36 teachers from Elementary and High School. The other consisted in four school sectors, charged with keeping students record data. Using qualitative method of contents' analysis. This study indicates its participants have social representations about high abilities. However, the results indicate that there are no gifted students enrolled in the researched institution. Furthermore, this study also suggests urgency in taking inclusive actions for gifted students at this school as well as continuing investigation.

Key words: High abilities, social representations, counseling.
\end{abstract}

\section{LAS ALTAS HABILIDADES Y EL RETO DE LA ATENCIÓN}

\begin{abstract}
Resumen
El estudio se realizó en una escuela federal de educación, ubicada en Río de Janeiro. Los objetivos generales establecidos para investigar las representaciones sociales de los maestros en alerta máxima y la existencia de habilidades de los estudiantes para cumplir con este perfil. Se utilizaron dos muestras diferentes. Uno compuesto por 36 profesores que trabajaron desde el 1 al 9 o grado de la escuela primaria y del 1 al $3^{\circ}$ año de la escuela secundaria y otro integrado por cuatro sectores de la universidad, responsables de los registros históricos de los estudiantes. El análisis de contenido se aplica en el tratamiento de los datos obtenidos. Los resultados mostraron que los encuestados los profesores tienen altas capacidades en las representaciones sociales y que no hay estudiantes con alta capacidad inscritos en la institución, de acuerdo con los sectores encuestados. Las
\end{abstract}


investigaciones sugieren la urgencia de implementar acciones inclusivas para las habilidades de alta en la escuela, así como la continuidad de esta investigación.

Palabras clave: competencias de alto, las representaciones sociales, la atención.

\section{INTRODUÇÃO}

Pessoas com altas habilidades são em geral, "indivíduos criativos e produtivos" (Renzulli, 2004), com características marcantes de um trabalho original, impregnado pelo novo e configurado pelo inédito (Fazenda, 1995). Destacam-se em diferentes áreas do saber e do fazer social e estão presentes em qualquer população, em torno de $1 \%$ a 10\% (Mettrau, 2000). Podem apresentar indicadores isolados ou combinados como: "notável desempenho, elevada potencialidade na capacidade intelectual geral, liderança, aptidão acadêmica específica, pensamento criador ou produtivo, talento especial para artes e capacidade psicomotora" (MEC 2006, s/p).

A Lei de Diretrizes e Bases da Educação No 9.394/96, em seu capítulo V. Da Educação Especial, prevê um ensino diferenciado, preferencialmente, na rede regular de ensino, para esses alunos. A lei encaminha diretrizes prevendo possibilidades educativas, desenvolvidas por professores especializados e capacitados.

Para efetivação das propostas legais, Renzulli (1994), Mettrau (2000) e Landau (2002) apontam a importância da "opinião e do juízo do professor" na identificação e indicação dos estudantes altamente capazes para os programas específicos de atendimento. Estes autores observam em seus trabalhos, uma "baixa qualidade de informação e formação" desses profissionais, nessa área específica. Segundo eles, esse déficit, vem prejudicando a implementação das ações previstas e regulamentadas na legislação, principalmente nas instituições de ensino, em geral.

A literatura especializada justifica a necessidade de estimulação sistematizada das potencialidades, também, para as crianças com altas habilidades o mais precocemente possível. Apresenta pontos relevantes aqui destacados e que devem ser observados nas propostas de programas de atendimento.

Landau (2002) propõe um Sistema Interativo de Superdotação entre o mundo interior da criança e o ambiente que desafia e estimula as habilidades: inteligência, criatividade e talentos. Mostra que o estímulo emocional deve ser 
oferecido pelo ambiente visando o fortalecimento do seu ego, transmitindo-lhe coragem para usar os seus talentos. Enquanto o estímulo intelectual proporciona a informação, o significado e o preparo para os desafios, o ambiente fornece a motivação, para a realização de toda a sua potencialidade.

O Modelo Triádico da Superdotação foi desenvolvido por Renzulli em 1985 e aperfeiçoado por Mönks em 1992, (conforme citado por Mettrau, 2007) com o objetivo de definir, explicar e diferenciar os termos superdotado e talentoso aplicados indiscriminadamente, no cotidiano. Ilustra ainda, as propriedades do "movimento, interação, mudança e energia contínuas", inerentes aos grupos de características, que o compõem. Trata-se de um conjunto relativamente bem definido de três grupos de características que se entrelaçam: a criatividade, 0 compromisso com a tarefa e uma habilidade acima da média. Ressalta que um único grupo de domínio, não determina a superdotação, mas a interseção central dos três anéis.

Na criatividade inclui-se a originalidade de pensamento, o gênio construtivo, a habilidade para deixar de lado convenções e procedimentos estabelecidos em detrimento de idéias originais. No compromisso com a tarefa há um refinamento e uma maneira centrada de motivação, concebida como um processo energizante elevado para resolver problemas, perseverança, resistência, trabalho duro, dedicação, confiança e crença em si para realizar projetos importantes, percepção de um maior sentido para identificar problemas e soluções. Essas pessoas são precursoras de um trabalho original, diferente (são visionárias). A habilidade acima da média apresenta duas formas organizadas para representar modos peculiares, com os quais os sujeitos se expressam em problemas reais: a habilidade geral refere-se à capacidades para processar informação, integrar experiências vividas para chegar a um resultado novo, buscar respostas apropriadas com vista a adaptação à novas situações, gerar pensamento abstrato. A habilidade específica visa adquirir conhecimentos padrões, realizar atividades de um tipo especializado dentro de uma gama restrita.

Mettrau (2007) demonstra no seu Diagrama do Funcionamento da Inteligência Humana, um movimento contínuo e integrado das expressões cognitiva, afetiva e criativa. Estas são distintas, porém, mantêm-se permanentemente, indissociáveis, em um desenvolvimento harmônico, dentro do grupo social. 
As diferentes investigações sobre as pessoas com altas habilidades convergem no sentido de que não se pode adotar um único critério na determinação da superdotação. Trata-se de um processo complexo, com múltiplos viéses a serem observados, como ficou demonstrado. Os dois objetivos gerais dessa investigação sondaram as representações sociais dos professores sobre as altas habilidades e a existência de alunos com esse perfil, indicados para atendimento nessa escola, que integra a rede regular de ensino da esfera federal, localizada no Rio de Janeiro.

\section{MÉTODO}

\section{Participantes}

Formaram-se dois tipos de amostras: A primeira, "probabilística, aleatória" (Richardson, 2008), constituída de 36 professores: 15 (10 ao $5^{\circ}$ ano), 12 (60 ao 90 ano) e 9 (10 ao $3^{\circ}$ ano do ensino médio). A segunda, "não probabilística intencional" (Richardson, 2008), composta por três Setores de Supervisão e Orientação Pedagógica/SESOP da escola, responsáveis pela registro histórico dos alunos, e o Setor de Educação Especial/SEE.

\section{Instrumentos}

Construiu-se um conjunto de três questionários abordando assuntos sobre o tema pesquisado. O primeiro direcionado aos professores. O segundo para os três SESOPs e o terceiro para o SEE. Os três questionários foram constituídos de questões fechadas (Sim ou Não), questões fechadas (Sim ou Não) com detalhamento e questões abertas objetivas.

\section{Procedimento}

Em 2006, realizou-se uma palestra para os professores do ensino fundamental (do $1^{\circ}$ ao $5^{\circ}$ anos) com o objetivo de introduzir o tema nessa escola, de modo a favorecer a formação de representações sociais por parte dos docentes. Observou-se interesse e reflexões interpessoais dentro do grupo, nesse período e em ocasiões de avaliação, houve referências a alunos que apresentavam características de altas habilidades.

Por meio das representações sociais nomeamos e definimos aspectos do cotidiano, interpretando-os, decidindo e posicionando-nos frente a eles. Estas estão relacionadas ao pensamento simbólico e a toda forma de vida mental que 
pressupõe linguagem. São influenciadas, construídas e mantidas socialmente, por meio da comunicação entre as pessoas no dia a dia, dentro de um determinado grupo social (Moscovici, 2003).

A coleta dos dados efetivou-se em 2008, com a distribuição randômica dos questionários para os docentes das diversas disciplinas que compõem a grade curricular de cada ano escolar e para os três SESOPs e o SEE. Para as questões fechadas, do tipo nominal e as questões abertas objetivas aplicou-se a operação básica da contagem do número de casos, anotando-se suas freqüências (Richardson, 2008). Com relação as questões fechadas com detalhamento, manteve-se o mesmo procedimento anterior para os itens Sim e Não, com o diferencial da análise do conteúdo no detalhamento das respostas. Nesse momento, buscou-se depreender os processos de elaboração e consolidação do sistema de pensamento que sustentam as práticas sociais (Jodelet, 1984, citado por Spink, 1993) dos professores dessa escola, ao seja as suas representações sociais em relação às altas habilidades.

\section{RESULTADOS}

Há que se esclarecer para melhor interpretação dos dados, o termo Unidade utilizado nas tabelas. Esta nomenclatura é a utilizada por essa escola, na organização do espaço onde funciona cada um dos segmentos da Educação Básica: Unidade I, professores do $1^{\circ}$ ao $5^{\circ}$ ano e Unidade II, professores do $6^{\circ}$ ao 90 ano do ensino fundamental. Unidade III, professores do $1^{\circ}$ ao $3^{\circ}$ ano do ensino médio.

Com relação à amostra dos professores, os resultados das questões que versavam sobre o conceito e caracterização das altas habilidades, mostraram que $100 \%$ ouviu falar em altas habilidades (pergunta 1), 75\% já percebeu esses alunos em algum momento de sua trajetória profissional (pergunta 2), mas apenas 50\% afirmou tê-los tido em sua classe (pergunta 4). Detalharam como características, principalmente, indicadores que determinam a capacidade acima da média em atividades especificamente acadêmicas, em sua maioria, conforme Tabela 1. 
Tabela 1.

Conceituação e Caracterização.

\begin{tabular}{cccccccccc}
\hline Unidade & \multicolumn{2}{c}{ I } & \multicolumn{2}{c}{ II } & \multicolumn{2}{c}{ III } & Total \\
Perguntas & & Sim & Não & Sim & Não & Sim & Não & \\
\hline 1 & No & 15 & & 12 & & 9 & & 36 \\
2 & No & 9 & 5 & 11 & 1 & 6 & 3 & 36 \\
4 & No & 6 & 6 & 9 & 2 & 3 & 6 & 36 \\
\hline
\end{tabular}

Na Pergunta 2 um respondente da Unidade I, não optou por nenhuma das duas opções, escrevendo "às vezes". Na Pergunta 4 três respondentes da Unidade I e um da Unidade II, também não optaram, mas registraram que "não sabiam" responder.

Para o grupo de perguntas relativas às políticas públicas e amparo legal, verificou-se que apenas $63 \%$ dos respondentes tinha informações sobre a existência do amparo legal para atendimento específico dessa clientela (pergunta 3) e $94 \%$ considerava importante indicá-los e atendê-los (pergunta 7 e 8), conforme Tabela 2.

Tabela 2.

Políticas Públicas e Amparo Legal.

Unidade I II III Total

\begin{tabular}{ccccccccc} 
Perguntas & & \multicolumn{1}{c}{ Sim } & Não & Sim & Não & Sim & Não & \\
\hline 3 & No & 12 & 3 & 8 & 4 & 3 & 6 & 36 \\
7 & No & 14 & & 11 & 2 & 9 & & 36 \\
8 & No & 14 & & 11 & 2 & 9 & & 36 \\
\hline
\end{tabular}

Para as pergunta 7 e 8 um respondente da Unidade I deixou em branco as duas opções e escreveu "não sei". Apenas um da Unidade II, marcou as duas opções.

As questões que tratavam do papel do professor e formação continuada apontaram que $19 \%$ dos docentes declarou saber lidar com esses alunos (pergunta 5), 28\% já comunicou aos SESOPs a existência deles em classe (pergunta 6), 89\% reconheceu ser o professor o mais qualificado para indicar e lidar com eles (pergunta 9) e 100\% da amostra solicitou mais informações sobre o tema (pergunta12), conforme Tabela 3. 
Tabela 3.

Papel do Professor e Formação Continuada.

\begin{tabular}{cccccccccc}
\hline Unidade & & \multicolumn{2}{c}{ I } & \multicolumn{2}{c}{ II } & \multicolumn{2}{c}{ III } & Total \\
Perguntas & & Sim & Não & Sim & não & Sim & Não & \\
\hline 5 & No & 2 & 11 & 3 & 8 & 2 & 5 & 36 \\
6 & No & 4 & 10 & 4 & 7 & 2 & 6 & 36 \\
9 & No & 12 & 2 & 12 & & 8 & 1 & 36 \\
12 & No & 15 & & 12 & & 9 & & 36 \\
\hline
\end{tabular}

Na Pergunta 5 dois respondentes da Unidade I e dois da Unidade III não marcaram as opções dadas, e escreveram "não sei", e um respondente da Unidade II também não optou, mas escreveu "mais ou menos". Já na Pergunta 6 um respondente da Unidade I não marcou opção, mas escreveu "comentei" e um respondente da Unidade II e um da Unidade III, deixaram em branco. $\mathrm{Na}$ Pergunta 9 um respondente da Unidade I não marcou opção.

A abordagem sobre a implantação de programas de atendimento específico para alunos com altas habilidades nessa escola, demonstrou que $67 \%$ dos participantes pensa ser possível essa modalidade de trabalho (pergunta 10) e $75 \%$ considerou ser esta uma atribuição do SEE (pergunta 11), conforme Tabela 4.

Tabela 4.

Programas de Atendimento.

\begin{tabular}{cccccccccc}
\hline Unidade & \multicolumn{3}{c}{ I } & \multicolumn{2}{c}{ II } & \multicolumn{2}{c}{ III } & Total \\
Perguntas & & Sim & Não & Sim & não & Sim & Não & \\
\hline 10 & No & 11 & 2 & 7 & 1 & 6 & 3 & 36 \\
11 & No & 13 & & 7 & 1 & 7 & 2 & 36 \\
\hline
\end{tabular}

Na Pergunta 10 dois respondentes da Unidade I não marcaram opção e escreveram "não sei". Na Unidade II, dois respondentes também não optaram e escreveram "não sei", um outro marcou as duas opções Sim e Não, e o outro deixou-as em branco. Na Pergunta 11, Na Unidade I, um respondente não optou e escreveu "não sei", e outro marcou as duas opções Sim e Não. Na Unidade II, um também, não optou, escreveu e marcou outra opção "não sei", outro marcou também as duas, e dois deixaram-nas em branco. 


\section{Resultados obtidos nos SESOPs e SEE}

Para o quesito que sondava a existência de alunos com altas habilidades nos três segmentos, houve unanimidade para a opção, Não (pergunta 1) com os seguintes detalhamentos: "Não há casos confirmados, há suspeitas"; "Há indicadores mas não há continuidade nesta investigação"; "Há orientação aos pais".

Afirmaram conhecer o amparo legal para atendimento diferenciado a esse alunado (pergunta 5) com apenas uma justificativa: "Conheço a legislação educacional". Divergiram quanto a implantação desta modalidade de atendimento no Colégio (pergunta 6) com os detalhamentos: "a escola possui uma infra-estrutura que pode ser adequada, bem como um corpo docente qualificado"; "Eu vejo aqui o Laboratório de Aprendizagem que poderia ser uma sala de recursos, temos professores com formação em psicopedagogia e áreas afins que poderiam estar a frente desses programas"; "Embora considere fundamental o atendimento diferenciado independente da legislação, por considerá-la inerente à democratização do ensino, tal proposta requer a participação de profissionais com qualificação ou pelo menos, orientação para tal".

Concordaram que o SEE seria o responsável por esse trabalho (pergunta 7) observando nos detalhamentos: "Acho que no momento da implantação sim, mas posteriormente, deveria se generalizar"; "Sim, principalmente porque assim está previsto na LDB"; "Não considero somente para a Educação Especial, pois tal atendimento é responsabilidade de todos que trabalham na Educação"; "Sim, porque são pessoas capacitadas".

Tabela 5.

Existência de Alunos, Políticas Públicas e Programas de Atendimento.

\begin{tabular}{ccccccccc}
\hline Unidade & & \multicolumn{2}{c}{ I } & \multicolumn{2}{c}{ II } & \multicolumn{2}{c}{ III } & Total \\
Perguntas & & Sim & Não & Sim & Não & Sim & Não & \\
\hline 1 & No & & 1 & & 1 & & 1 & 3 \\
5 & No & 1 & & 1 & & 1 & & 3 \\
6 & No & 1 & & & 1 & 1 & & 3 \\
7 & No & 1 & & 1 & & 1 & & 3 \\
\hline
\end{tabular}

As respostas das perguntas totalmente, abertas foram transcritas na íntegra, atentando-se para o critério descritivo das mesmas. Declararam na pergunta 2, que a indicação desses alunos teria sido efetivada "pelos professores 
da Unidade"; "E por profissionais que trabalharam / trabalham com o aluno antes de ingressar nessa Unidade". Sobre quais as capacidades ou destaques foram observadas nos alunos indicados? Pergunta 3, responderam: "Um destaque, uma maior habilidade em determinada área". E se está sendo desenvolvido algum tipo de ação para atendê-los? Pergunta 4. Houve unanimidade para a opção Não.

\section{DISCUSSÃO}

O cruzamento dos dados dos três instrumentos demonstrou que a totalidade dos respondentes já ouviu falar sobre as altas habilidades. Esclareceram que seu conhecimento sobre o tema formou-se por meio de informações obtidas na mídia em geral, trocas interpessoais informais e formais no âmbito profissional (reuniões pedagógicas, conselhos de classe, histórico de alunos, SESOPs) e Internet. Houve um esclarecimento sobre uma experiência na família e dois professores declararam terem recebido um conhecimento sistematizado na graduação e em encontros de formação continuada.

Observou-se que os detalhamentos reportam-se, em sua maioria, à descrição de características de cunho acadêmico, notadamente para a capacidade cognitiva acima da média. Isso pode ser notado no contido no modelo dos três anéis de Renzulliano, mas sempre relacionadas às atividades escolares.

Referenciando Renzulli (1994), não houve um índice significativo para os quesitos criatividade e envolvimento com a tarefa (motivação), características essas que compõem o seu Modelo Triádico de Superdotação. Não foram elencados quesitos como: a sociabilidade, a afetividade e dificuldades em áreas de desenvolvimento (relacionamento, conduta), também, ressaltados na literatura especializada.

Os participantes declararam ter insegurança e dúvida quanto ao uso dos diferentes conceitos utilizados na literatura especializada. Citaram termos como: talentoso, esforçado, com altas habilidades, superdotado. Referiram-se aos mitos que circulam nos diversos âmbitos da sociedade acerca desses sujeitos e que foram analisados por Winner (1998). Essa dificuldade ficou evidente quando detalharam "que observam em sala de aula alunos com certas características, mas que apenas comentam entre si ou mesmo nos Setores responsáveis" evitando fazê-lo oficialmente. 
O resultado permitiu inferir que o conhecimento dos docentes sobre o tema em questão é superficial, corroborando com a literatura especializada, nesse sentido. Esta constatação aponta para a necessidade de um investimento imediato, por parte da instituição pesquisada, em capacitação sobre o tema, de forma a assegurar aos seus profissionais maior segurança para notar, indicar e lidar com estes alunos. Além disso, atenderia à solicitação de $100 \%$ dos respondentes que têm interesse em receber mais subsídios.

Os três Setores de Supervisão e Orientação Pedagógica (SESOP) e o Setor de Educação Especial afirmaram não haver registro da existência de alunos com altas habilidades na escola. A afirmativa em pauta lança um paradoxo relevante, uma vez que os referidos Setores relataram haver recebido novos alunos com indicação de altas habilidades em seus históricos, embora tenham considerado serem apenas casos ainda não confirmados, somente suspeitas de apresentarem tais indicadores. As indicações a que se referiram teriam sido efetivadas por instituições, professores e outros profissionais que lidaram com os alunos antes do ingresso deles nessa escola, sem que se tivesse dado continuidade ao processo de investigação.

Outro contraponto a ser discutido é o conhecimento da legislação pelos SESOPs e SEE, com relação ao direito assegurado para essa clientela, a um atendimento específico. No entanto, houve unanimidade nas respostas, de que até aquele momento não estavam sendo desenvolvidas ações, nem tampouco, havia previsão de implantação de programas, em virtude de não terem uma equipe qualificada. Chama a atenção outro relato dos Setores, de que se faz orientação às famílias quanto à possibilidade de seus filhos possuírem altas habilidades, sem contudo detalharem a natureza desse trabalho.

Em suma, constatou-se pelos resultados obtidos que há representação social por parte dos professores, SESOPs e SEE sobre as altas habilidades. Em relação ao objetivo que sondava a existência de registro de indicação de alunos com altas habilidades, os resultados mostraram dados contraditórios nas respostas dos professores, dos SESOPs e do SEE. Embora, oficialmente, a escola declarasse não haver registro desses alunos em suas classes, foi possível perceber nos relatos dos três âmbitos pesquisados, indícios da presença desses alunos, corroborando com os estudos citados anteriormente.

Ao se considerar o percentual estabelecido na literatura especializada, de que há ocorrência de $1 \%$ a $10 \%$ dessas pessoas em qualquer grupamento, 
inferiu-se que no corpo discente dessa instituição, estão inseridos alunos com altas habilidades, desassistidos, aos quais está sendo negado o direito de receberem uma educação compatível com a sua necessidade especial, como está determinado na legislação.

Essa é uma realidade denunciada em trabalhos desenvolvidos neste campo há algum tempo e que continua se mantendo, apesar do aprimoramento das leis e do incentivo e apoio para a implantação de ações, pelos órgãos governamentais. As leis são claras quanto ao efetivo atendimento dessa clientela nos diferentes âmbitos e níveis educacionais (LDB No 9.394/96, Capítulo V, Artigos 58, 59 e 60). É uma determinação a ser cumprida, não uma opção de qual clientela ou necessidade atender, mesmo sendo uma tarefa árdua e complexa. Se assim não fosse, não estaria posta em lei, indicando tal necessidade em consonância com as características desse alunado.

Nesse sentido, vale ressaltar a iniciativa da Secretaria de Educação Especial do Ministério da Educação de implantar em parceria com as Secretarias de Educação em todas as Unidades da Federação, os Núcleos de Atividades de Altas Habilidades/Superdotação (NAAH/S), disponibilizando recursos didáticospedagógicos, formação de profissionais especializados para atendimento aos desafios acadêmicos, sócio-emocionais (MEC, 2006) e motivacionais dos alunos com esse perfil e dar suporte às instituições educacionais que se interessem em atendê-los.

Fica evidente a importância e premência em se reformular os cursos de formação de professores incluindo disciplinas que tratem, também, das altas habilidades, no intuito de qualificar melhor os docentes, sanando ou pelo menos minimizando suas demandas nessa especialidade. Além disso, as escolas podem promover centro de estudos e outros momentos que incluam o estudo desse tema.

É orientação legal de que a formalização do registro de qualquer indicação feita pelo professor ou demais profissionais e setores da escola atual e anteriores deverá constar do histórico escolar do aluno, mesmo que a instituição não desenvolva ações de atendimento imediato. Este é um direito deste e dever da escola.

A realização desse procedimento possibilitará a veiculação das informações referentes à vida escolar do aluno no âmbito escolar garantindo, minimamente, a solicitação dos respondentes de conhecer a história do seu aluno. Dessa forma, 
poderão melhor compreender suas atitudes e desempenho, facilitando a busca de conhecimentos e estratégias individuais e/ou conjuntas na condução do trabalho didático direcionado à potencialização das suas capacidades e habilidades, em qualquer área. Ressalte-se que esses cuidados são geralmente, praticados no cotidiano das escolas, quando da indicação, acompanhamento e orientação de alunos por outros tipos de especificidades, em geral (por exemplo, déficit visual, auditivo, síndromes, transtornos, disciplina, etc.).

A parceria família-escola é essencial, pois possibilita trocas valiosas de informações sobre o estudante (seus gostos, interesses, dificuldades, etc), auxiliando a condução de estratégias alternativas na lida com o mesmo no cotidiano escolar. É de grande valia na resolução de possíveis situações ou problemas passados, presentes ou futuros no grupo social, em geral. Ainda numa perspectiva otimista, proporciona que a família uma vez informada, busque suporte fora da escola e amplie suas ações para o enriquecimento acadêmicosócio-cultural, quando for o caso.

A circulação de informações sobre altas habilidades no campo educacional é fundamental. Porém, não se deve restringir apenas ao conceito e características marcantes, mas há que se viabilizar subsídios sobre a prática educacional relativa ao processo ensino-aprendizagem, elaboração de programas, planejamento de atividades, dentre outras. Isso porque segundo os estudiosos da área, as pessoas com altas habilidades demandam ações criativas e de pesquisas que envolvem alta qualidade e profundidade por parte de toda equipe pedagógica. Essas ações irão contribuir certamente, para o crescimento acadêmico, motivacional e criativo do grupo de pertencimento do estudante, em princípio, ampliando-se para toda a comunidade escolar. Portanto, investir em ações educativas para as pessoas com altas habilidades é implementar educação de qualidade e desenvolvimento para todos no seu entorno.

No entanto, abre-se uma lacuna frente a questões que mereceriam maiores esclarecimentos e que foram geradas a partir dessa investigação. Talvez sejam temáticas para próximos estudos: Por que os professores não formalizam a indicação desses alunos junto aos Setores (SESOPs e SEE) responsáveis? Ou quem sabe o inverso, porque os Setores (SESOPs e SEE) responsáveis por essas ações, não formalizam as indicações, suspeitas e/ou comentários dos professores, uma vez que conhecem a legislação? Onde estão os alunos com 
indicadores de altas habilidades recebidos de outras instituições e percebidos pelos professores?

Finalizando, há que se ressaltar, que não se pretende generalizar os resultados encontrados nessa investigação. Mas entende-se que os mesmos serão importantes como ponto de referência no planejamento de outras sondagens sobre o tema ou também, como pré-requisito para implementar ações no âmbito educacional, em geral e especial na área das altas habilidades, em particular.

Destaca-se a importância de se introduzir e aumentar o acervo de informações sobre o tema nas escolas e universidades. Finalmente, não se pode deixar de refletir sobre a contribuição social desse estudo complexo e delicado, mas que em contrapartida, foi instigante e desafiador por se tratar de um problema real.

\section{REFERÊNCIAS}

Ministério da Educação e Cultura (1996). Lei No. 9.394 Diretrizes e Bases da Educação Nacional. Brasília: Editora do Brasil.

Ministério da Educação e Cultura. Secretaria de Educação Especial. (2006). Documento Orientador Execução da Ação dos Núcleos de Atividades de Altas Habilidades / Superdotação. Brasília.

Fazenda, I. C. A. (1995). Interdisciplinaridade: um projeto em parceria. São Paulo: Edições Loyola.

Landau, E. (2002). A Coragem de ser superdotado. Trad. De Sandra Miessa. Altas habilidades em foco. São Paulo:Arte \& Ciência Editora.

Mettrau, M. B. (2000). Inteligência Patrimônio Social. Rio de Janeiro: Qualitymark Editora Ltda.

Mettrau, M.B. (2007). Educação Moral, Inteligência e Altas Habilidades in Rumos e Resíduos da MORAL Contemporânea. Niterói: Muiraquitã.

Moscovici, S. (2003). Representações sociais: investigações em psicologia social. Petrópolis: Ed. Vozes.

Renzulli, J. S. (1994). El Concepto de los três anillos de la superdotacion: um modelo de desarrollo para una productividad creativa. In Y. Benito (Org.), Intervención e Investigación Psicoeducativas en Alumnos Superdotados (pp. 41-71). Salamanca: Amarú Ediciones. 
Renzulli, J. S. (2004). O que é esta coisa chamada superdotação, e como a desenvolvemos? Uma retrospectiva de vinte e cinco anos. Educação - Porto Alegre - RS, 52(1), $75-131$.

Richardson, R. J., \& Col. (2008). Pesquisa Social Métodos e Técnicas (3a ed.). São Paulo: Editora Atlas S. A.

Spink, M. J. (1993). O conhecimento no cotidiano e as representações sociais na perspectiva da psicologia social. São Paulo: Editora Brasiliense.

Winner, E. (1998). Crianças Superdotadas mitos e realidades. Porto Alegre: Artes Médicas.

Contato: celiapaz13@gmail.com; marsyl@superig.com.br

Recebido em: 07/02/2010

Revisado em: 11/05/2010

Aceito em: 15/06/2010 